are used, due presumably to the kind of flow prevailing. Experiments have been carried out using different gaps between rotating cylinders, allowing for a wide range in the ratio of particle size to length of annular gap. Similar results for slip at the cylinder walls have been obtained under the various conditions. Special research viscometers for dealing with settling suspensions and methods of analysing the results obtained were next described. Following further discussion by the meeting, under the chairmanship of S. F. Freeman (Mars, Ltd.), of proposed new viscometers, visits were made to the laboratories of the University where rheological work was proceeding.

E. W. J. Mardles

\section{UNIVERSITIES' FEDERATION FOR ANIMAL WELFARE}

\section{SILVER JUBILEE}

\section{By Prof. A. N. WORDEN}

$\mathrm{T}$ HE British Science Guild, which derived from the British Association for the Advancement of Science, was formed for the purpose of promoting the application of scientific methods and results to public affairs. In 1926 its honorary secretary was C. W. Hume and its most active member Sir Richard Gregory, then editor of Nature. The Guild has since been re-absorbed into the British Association; but one of its unofficial offspring, the University of London Animal Welfare Society, or ULAWS (now expanded into the Universities' Federation for Animal Welfare, or UFAW) is still very much alive and has recently celebrated its jubilee by a dinner held in London. It was Major Hume's thesis that the right relations between man and his fellow creatures were a proper study for the attention of university people as such. His first aim in founding the University of London Animal Welfare Society was to secure the support of veterinarians and zoologists; but the veterinary profession was at that time largely at variance with animal welfare movements. A contemporary vivisection controversy found the Society attacked by the anti-vivisection societies and suspected by experimentalists of harbouring in its ranks those of the category since dubbed 'cryptoantivivs'.

Major Hume's refusal to bow before these attacks, or to be discouraged by the initial apathy of the majority of those whose support he solicited, was steadfast. By 1939 hundreds of members and thousands of subscribers had been enrolled, funds from legacies and broadcast appeals had accrued, and the movement had been extended to other universities. In the same year it was decided that the now extensive educational efforts should be backed by original work, and a Scientific Investigations Committee was accordingly formed. Small grants were made for work on rabbit ecology, at the Bureau of Animal Population, Oxford, and for some studies on euthanasia in dogs in the Department of Pharmacology at the same University.

War, the early demise of the Federation's secretary and the destruction of its offices by enemy action naturally hampered many projects. On one enter. prise, however, work was continued, and by 1943 it was possible to begin the preparation for publication of a standard text-book upon the care and management of laboratory animals. The support of research workers for such a work was world-wide. Literally hundreds of scientific workers offered their support and the subsequent book, published some four years later, obviously filled a very real need. Only the anti-vivisectionist Press failed to accord it a most favourable reception.

Shortly after the conclusion of hostilities, the Federation made a substantial grant for research on rabbit ecology and control by the Department of Animal Health, University College of Wales, Aberystwyth. It had long been felt that trapping, while a barbarous procedure, was probably an unsound practice from the agricultural point of view, but scientific proof was wanting. These studies continued for more than four years, and attracted the interest and collabora. tion of official bodies. One of the county agricultural executive committees initiated a widespread attempt at rabbit control based upon methods investigated by the workers in the Department of Animal Health. The reports of the extensive investigations upon control measures, and upon the damage to pastures inflicted by rabbits, are at present being prepared for full publication. The information available by 1950 was placed before the Home Office Committee on Cruelty to Wild Animals. It is evident from its report (Cmd. 8266) that the Committee was duly impressed by the evidence given. The objective presentation to a departmental committee by an animal welfare organization of factual scientific material must have been something of a novelty; but it is, of course, this very combination of human. itarian outlook and scientific approach that characterizes the Universities' Federation for Animal Welfare and places it in the category of a scientific society.

Substantial support has more recently been given to investigations relating to the electrocution and electro-anæsthesia of animals. At present these studies are being undertaken by a veterinary physiologist attached to the Neuropsychiatric Research Centre, Whitchurch Hospital, Cardiff, in the hope of yielding much-needed information on the painlessness or otherwise of electrocution and electro-stunning apparatus now in use, and upon the future possibilities of electroplectic anæsthesia.

Yet another problem supported by the Federation is that of the humane destruction of whales. Here much of practical value has already been achieved in work undertaken at sea by one of the British whaling companies, but the full results are not yet available for study.

These original investigations, while forming a heavy burden upon the slender funds of any charitable organization, have not been pursued to the detriment of educational work at home or abroad. The $U F A W$ Courier is widely read, and a great deal of lecturing is carried out by members of the staff and by cooperating men of science. Before the War, membership was extended so as to include not only university men and women but also those members of the learned professions who were not university graduates.

From the first twenty-five years there is therefore much of which the Federation has cause to be proud. Its officials feel, however, that it is still extremely young. They note with satisfaction the birth of kindred ideas elsewhere. The recent formation in the United States of an Animal Care Panel, by veterinarians and scientific workers engaged in animal 
experimentation, is one such example. From its "temporary war-time address" (284 Regent's Park Road, Finchley, London, N.3) the Federation has built up extensive relationships that bode well for the future treatment of animals. There is no shortage of problems, and even though in some veterinary and laboratory circles there still remains a suspicion of anything termed 'animal welfare', this prejudice will finally be broken down by further deeds. In respect of the laboratory world alone, it is fair comment that the Federation's activities have tended to aid both the well-being of the animals themselves (which is largely a husbandry problem) and the value of them for experimental purposes. The Federation is concerned not with the sterile argument of whether experiments on living animals are justified, but with the best conditions in which laboratory animals may be maintained. Dr. E. C. Morland, formerly editor of the Lancet, wrote to Major Hume after the publication of the "Handbook" to congratulate the Federation for ". . . mediating with rare insight between two irreconcilable combatants. It relieved my mind of the misery of watching it go on, year in and year out and, it seemed, for ever. Accept the thanks of one who knows."

\section{CARNEGIE TRUST FOR THE UNIVERSITIES OF SCOTLAND}

\section{ANNUAL REPORT FOR 1949-50}

$\mathrm{T}$ HE outstanding feature of the forty-ninth annual report of the Carnegie Trust for the Universities of Scotland*, which covers the academic year 194950 , is the increased expenditure on research schemes, the total of $£ 34,088$ being the largest thus far required in the history of the Trust for postgraduate study and research. From surpluses at its disposal from the eighth quinquennial distribution to the universities and colleges, the Committee made extra grants of $£ 13,000$ each to St. Andrews and Aberdeen, and $£ 20,000$ each to Glasgow and Edinburgh. From the beginning of the year under review, the value of the research scholarships was raised from $£ 250$ to $£ 300$, the senior scholarships from $£ 400$ to $£ 450$, and the fellowships from $£ 700$ to $£ 800$ with a possible further $£ 50$ for exceptional expenses. Expenditure on these awards now exceeds $£ 12,000$ a year, and the Committee proposes in future to invite nominators to these scholarships to say privately whether a trial year in the first place is desirable. During this trial the scholarship would be $£ 200$ and would be tenable at the parent university under close supervision of the nominator or other member of the university department in which the scholar proposes to work.

Block grants to the four Universities for research at home or abroad by members of staff have been extended, from October 1950 , by a tentative scheme to involve not more than fifteen specially selected members of the university staffs in each year who will be given leave of absence for three to twelve months to prosecute lines of research on which they have already made such progress that conference with workers in the same fields in other countries is

* Carnegie Trust for the Universities of Scotland. Forty-ninth Annual Report (for the Year 1949-50), submitted by the Executive Committee to Trustees on February $26,1951 . \mathrm{Pp}$. iv +70. . $^{\text {(Edin }}$ -
burgh : Carnegie Trust for the Universities of scotiand, 1951.) highly desirable. Six of these awards each year will be for travel to, and maintenance in, the United States. The Committee is also continuing, particularly in co-operation with the publications committees of the universities, its system of guaranteeing against loss books which are the fruit of sustained research on the part of their authors, but which are of a nature likely to have only a limited public. Further assistance has also been given to learned societies in Scotland in the publication of their transactions and journals, as well as, through the universities, to the Third Statistical Account.

Awards of fellowships, scholarships and grants for 1950-51 are detailed in the report, which also includes, besides reports on the work of investigators under the research scheme during the year 1949-50 and from the superintendent of the laboratory of the Royal College of Physicians, lists of publications by fellows, scholars and recipients of grants and of assisted papers, together with details of assistance to students and an abstract of accounts for 1949-50. Assistance to students has been confined to those who, for adequate reasons, had no bursary from a local education authority or whose circumstances and exceptional merit enabled the Committee to give assistance under Clause $B$ of the Trust Deed. The average payment per beneficiary was $£ 21$, as against $\mathfrak{f 1 5}$ in previous years, and three hundred students benefited. The Committee notes with regret a severe decline in repayments by former beneficiaries, only $£ 1,160$ having been repaid as against $£ 5,379$ in the peak year of 1946-47.

\section{CHEMISTRY AT THE UNIVERSITY OF SYDNEY}

\section{GIFT FOR NEW BUILDING}

N $\mathrm{N}$ anonymous donor has recently presented to A the University of Sydney a sum of $£ 100,000$. This, according to the official announcement by the vice-chancellor, Prof. S. H. Roberts, has been "given and accepted on the sole condition that it is to be used for the building of the first wing of a new Chemistry School, and in the hope that it will stimulate other donors".

Chemistry in the University of Sydney has a history going back a century, beginning with the arrival in 1852 of the Hon. John Smith-previously assistant professor of chemistry in Marischal College, Aberdeen-as "Professor of Chemistry and Experimental Physic". About 1874 a separate chair of chemistry was instituted, with Archibald Liversidge as its first occupant. Following him have been C. E. Fawsitt (1907-46) and R. J. W. Le Fèvre (1946-). From 1913 there has also been a chair of pure and applied organic chemistry, all four holders of whichSir Robert Robinson, John Read, James Kenner, J. C. Earl-are now living in Great Britain.

Of the laboratories set up by Smith no signs remain. Those now in use are grouped around a nucleus laid out in 1889 by Liversidge. At intervals, various temporary and permanent additions have been made, so that in 1951 chemistry has available some $100,000 \mathrm{sq}$. ft. of floor space. This is not at all conveniently or efficiently arranged. In the University of Sydney a large number of students take chemistry 